\title{
Hubungan Antara Efikasi Diri dengan Kualitas Hidup Pasien Hipertensi di Wilayah Kerja Puskesmas Silo Jember
}

\section{(The Relationship of Self Efficacy and Quality of Life of Hypertension Patients in Silo-Public Health Center Jember)}

\author{
Lilis Susanti, Murtaqib, Kushariyadi \\ Fakultas Keperawatan Universitas Jember \\ Jl. Kalimantan No. 37 Kampus Tegal Boto Jember Telp./Fax. (0331) 323450 \\ email: murtaqib999@yahoo.co.id
}

\begin{abstract}
Hypertension is an increase in systolic blood pressure> $140 \mathrm{mmHg}$ and diastolic> $90 \mathrm{mmHg}$. Hypertension can cause a low quality of life, this is due to the effects of the disease. One factor that can affect quality of life is self-efficacy. Self-efficacy is self-confidence in one's ability to produce an achievement. This study aims to analyze the relationship between self-efficacy and quality of life of hypertensive patients in the working area of Silo Public Health Center Jember. The study design used analytic correlations with a cross sectional approach. Data collection on self-efficacy variables using the general questionnaire perceived self efficacy scale and on the quality of life variables using the whoqol-bref questionnaire. Data analysis using Spearmen rank test with a significance level of 0.05 . The results showed that self-efficacy in the good category was $76.9 \%$. The quality of life in the medium category is $70.3 \%$. There is relationship between self-efficacy and quality of life of hypertensive patients in the working area of Silo Public Health Center Jember of Silo Jember Health Center ( $p$ value $<0.001$; $r=0.356)$. The higher self-efficacy, the better the quality of life. Nurses can provide education and motivation in improving the self-efficacy of hypertensive patients.
\end{abstract}

Keywords: hypertension, self efficacy, quality of life

\begin{abstract}
Abstrak
Hipertensi merupakan peningkatan tekanan darah sistolik $>140 \mathrm{mmHg}$ dan diastolik $>90 \mathrm{mmHg}$. Hipertensi dapat menyebabkan kualitas hidup rendah, hal ini dikarenakan efek dari penyakit. Salah satu faktor yang dapat mempengaruhi kualitas hidup adalah efikasi diri. Efikasi diri merupakan keyakinan diri dalam kemampuan seseorang untuk menghasilkan suatu pencapaian. Penelitian ini bertujuan untuk menganalisis hubungan antara efikasi diri dengan kualitas hidup pasien hipertensi di Wilayah Kerja Puskesmas Silo Jember. Desain penelitian menggunakan korelasional analitik dengan pendekatan cross sectional. Pengumpulan data pada variabel efikasi diri menggunakan kuesioner general perceived self efficacy scale dan pada variabel kualitas hidup menggunakan kuesioner whogolbref. Analisis data menggunakan uji spearmen rank dengan tingkat signifikansi 0,05 . Hasil penelitian menunjukkan bahwa efikasi diri pada kategori baik yaitu 76,9\%. Nilai kualitas hidup pada kategori sedang yaitu $70,3 \%$. Terdapat hubungan antara efikasi diri dengan kualitas hidup pasien hipertensidi wilayah kerja Puskesmas Silo Jember ( $p$ value $<0,001 ; r=0,356)$. Semakin tinggi efikasi diri maka akan semakin baik kualitas hidupnya. Perawat dapat memberikan edukasi maupun motivasi dalam meningkatkan efikasi diri pasien hipertensi.
\end{abstract}

Kata kunci: hipertensi, efikasi diri, kualitas hidup 


\section{Pendahuluan}

Hipertensi merupakan suatu keadaan ketika seseorang mengalami peningkatan tekanan darah diatas batas normal [1]. Penyakit ini dapat memicu terjadinya penyakit lain seperti stroke, dimana penyakit ini dapat menyebabkan seseorang merasa kesulitan untuk melakukan aktivitas sehari-hari, sehingga dapat dikatakan bahwa hipertensi mempunyai pengaruh terhadap kualitas hidup seseorang [2]. Hipertensi dapat menyebabkan kualitas hidup menjadi rendah, baik dari segi fisik, psikologis, hubungan sosial dan lingkungan[3].

Kualitas hidup akan membaik apabila individu mampu menerima penyakit yang dialami dan patuh terhadap pengobatan. Faktor yang dapat meningkatkan kepatuhan ini adalah efikasi diri. Kualitas hidup seseorang meningkat pada pasien yang memiliki efikasi diri baik dan menjalani rutinitas sehari-hari karena tanpa adanya suatu beban [4]. Individu yang memiliki efikasi diri yang rendah memiliki strategi koping yang berfokus pada emosi karena seseorang percaya tidak ada yang dapat dilakukan untuk mengubah situasi yang sedang mereka hadapi [5]. Mengukur efikasi diri pada pasien hipertensi merupakan langkah penting menuju perbaikan dalam mengontrol hipertensi [6].

Penyakit tidak menular hipertensi memiliki prevalensi kejadian terbanyak [7]. Tahun 2025 mendatang, diprediksi orang dewasa di seluruh dunia akan mengalami hipertensi sebanyak 29\% [8]. Hasil studi pendahuluan yang dilakukan di wilayah kerja Puskesmas Silo Jember, penyakit hipertensi menempati urutan ketiga dari 11 penyakit tidak menular lainnya. Hasil penelitian terkait efikasi diri pasien hipertensi dari 483 pasien, setengah dari pasien memiliki efikasi diri yang rendah [9]. Sedangkan hasil penelitian terkait kualitas hidup pasien hipertensi didapatkan hasil bahwa dari 96 responden, 57,9

$\%$ pasien mengalami kualitas hidup buruk [2].

Penderita hipertensi harus memiliki keyakinan diri terhadap kondisinya, efikasi diri dibutuhkan penderita hipertensi untuk meningkatkan kesehatannya [10]. Efikasi diri yang buruk akan memberikan dampak yang buruk pada individu [11]. Oleh karena itu upaya preventif sangat dibutuhkan. Selain itu untuk meningkatkan kualitas hidup pasien hipertensi dapat dilakukan dengan meningkatkan kesadaran mereka terkait dengan pencegahan hipertensi dan mengembangkan kebiasaan hidup sehat melalui pendidikan kesehatan pada pasien hipertensi [12].

Berdasarkan fenomena diatas, peneliti tertarik untuk melakukan sebuah penelitian terkait Hubungan antara efikasi diri dengan kualitas hidup pasien hipertensi di wilayah kerja
Puskesmas Silo Jember.

\section{Metode Penelitian}

Penelitian ini merupakan penelitian korelasional analitik dengan pendekatan cross sectional. Populasi dalam penelitian ini yaitu pasien hipertensi di wilayah kerja Puskesmas Silo Jember dari bulan Juli sampai dengan bulan Oktober 2018 yaitu sebanyak 118 orang. Sampel yang diambil yaitu sebanyak 91 responden dengan teknik purposive sampling. Penelitian ini dilakukan secara door to door, mengikuti serangkaian kegiatan pengelolaan penyakit kronis (Prolanis) dan posyandu lansia yang diadakan satu bulan sekali di wilayah kerja Puskesmas Silo Jember. Kuesioner pada variabel efikasi diri yaitu menggunakan general perceived self efficacy scale, dan pada variabel kualitas hidup menggunakan kuesioner whoqol- bref.

Analisis data menggunakan analisis univariat dan bivariat. Analisis univariat digunakan untuk menggambarkan karakteristik dari masing-masing variabel sedangkan untuk analisis bivariat menggunakan uji Spearman dengan tingkat signifikansi 0,05.

\section{Hasil Penelitian \\ Karakteristik Responden}

Tabel 1. Distribusi karakteristik responden berdasarkan usia pasien Hipertensi di wilayah kerja Puskesmas Silo Jember (Januari-februari; 2019; n : 91)

\begin{tabular}{|l|r|c|}
\hline Variabel & Mean & SD \\
\hline Usia (tahun) & 58,93 & 11,07 \\
\hline Sumber: Data & Primer & Penelitian, Januari- \\
Februari 2019 & &
\end{tabular}

Februari 2019

Tabel 1 menunjukkan bahwa nilai ratarata dari usia pasien hipertensi di wilayah kerja Puskesmas Silo Jember adalah 58,93 tahun dengan nilai standar deviasi 11,07.

Tabel 2. Distribusi karakteristik responden berdasarkan Lama Menderita pasien Hipertensi di wilayah kerja Puskesmas Silo Jember (Januari-februari; 2019; n : 91)

\begin{tabular}{|l|c|c|}
\hline Variabel & Median & Min-Maks \\
\hline Lama Menderita & 3,00 & $1-10$ \\
\hline
\end{tabular}

Sumber: Data Primer Penelitian, JanuariFebruari 2019

Tabel 2 hasil distribusi lama menderita pada pasien hipertensi diwilayah kerja Puskesmas Silo Jember didapatkan nilai tengah 3,00 tahun dengan lama menderita hipertensi minimal 1 tahun dan lama menderita hipertensi maksimal 10 tahun. 
Tabel 3. Distribusi karakteristik Responden berdasarkan jenis kelamin, pekerjaan dan pendidikan pada pasien Hipertensi di wilayah kerja Puskesmas Silo Jember (Januari-februari 2019; n:91)

\begin{tabular}{|l|c|c|}
\hline Variabel & Jumlah & $\begin{array}{c}\text { Presentase } \\
(\%)\end{array}$ \\
\hline $\begin{array}{l}\text { 1. Jenis Kelamin } \\
\text { a. Laki-laki }\end{array}$ & & \\
b. Perempuan & 19 & 20,9 \\
\hline $\begin{array}{l}\text { 2. Pendidikan } \\
\text { a. Tidak Sekolah }\end{array}$ & 32 & 79.1 \\
b. SD & 45 & 33,0 \\
c. SMP & 9 & 49,5 \\
d. SMA & 7 & 9,9 \\
e. Perguruan Tinggi & 0 & 7,7 \\
\hline 3. Pekerjaan & & 0 \\
a. Ibu Rumah Tangga & 48 & 52,7 \\
b. Tani atau Pedagang & 24 & 26,4 \\
c. PNS & 1 & 1,1 \\
d. Wiraswasta & 5 & 5,5 \\
e. Karyawan swasta & 4 & 4,5 \\
f. Tidak bekerja & 6 & 6,6 \\
g. Pensiun & 3 & 3,3 \\
\hline
\end{tabular}

Sumber: Data Primer Penelitian, JanuariFebruari 2019

Tabel 3 menunjukkan bahwa dari 91 pasien hipertensi di wilayah kerja Puskesmas Silo Jember distribusi karakteristik responden berdasarkan jenis kelamin menunjukkan bahwa perempuan lebih banyak yaitu 72 pasien dengan presentase $79,1 \%$ sedangkan laki-laki sebanyak 19 orang dengan presentase $20,9 \%$. Tingkat Pendidikan pasien hipertensi terbanyak adalah pada pendidikan SD yaitu sebanyak 45 pasien dengan presentase $49,5 \%$. Sedangkan dari tuju jenis pekerjaan, riwayat pekerjaan responden terbayak adalah lbu rumah tangga yaitu sebanyak 48 pasien dengan presentase $52,7 \%$ dan pekerjaan PNS menempati urutan terakhir yaitu satu orang dengan presentase $1,1 \%$.

\section{Efikasi Diri}

Tabel 4. Distribusi Efikasi diri pasien hipertensi di Wilayah kerja Puskesmas Silo Jember (Januari-februari 2019; n:91)

\begin{tabular}{|l|c|c|}
\hline Variabel & Jumlah (Orang) & Presentase (\%) \\
\hline Efikasi Diri & & \\
a. Buruk & 21 & 23,1 \\
b. Baik & 70 & 76,9 \\
\hline
\end{tabular}

Sumber: Data Primer Penelitian, JanuariFebruari 2019

Tabel 4 menunjukkan bahwa sebagian besar pasien hipertensi di wilayah kerja Puskesmas Silo Jember memiliki efikasi diri baik yaitu sebanyak 70 pasien dengan presentase sebesar $76,9 \%$.
Tabel 5. Distribusi indikator Efikasi diri pasien hipertensi di Wilayah kerja Puskesmas Silo Jember (Januari-februari 2019; n:91)

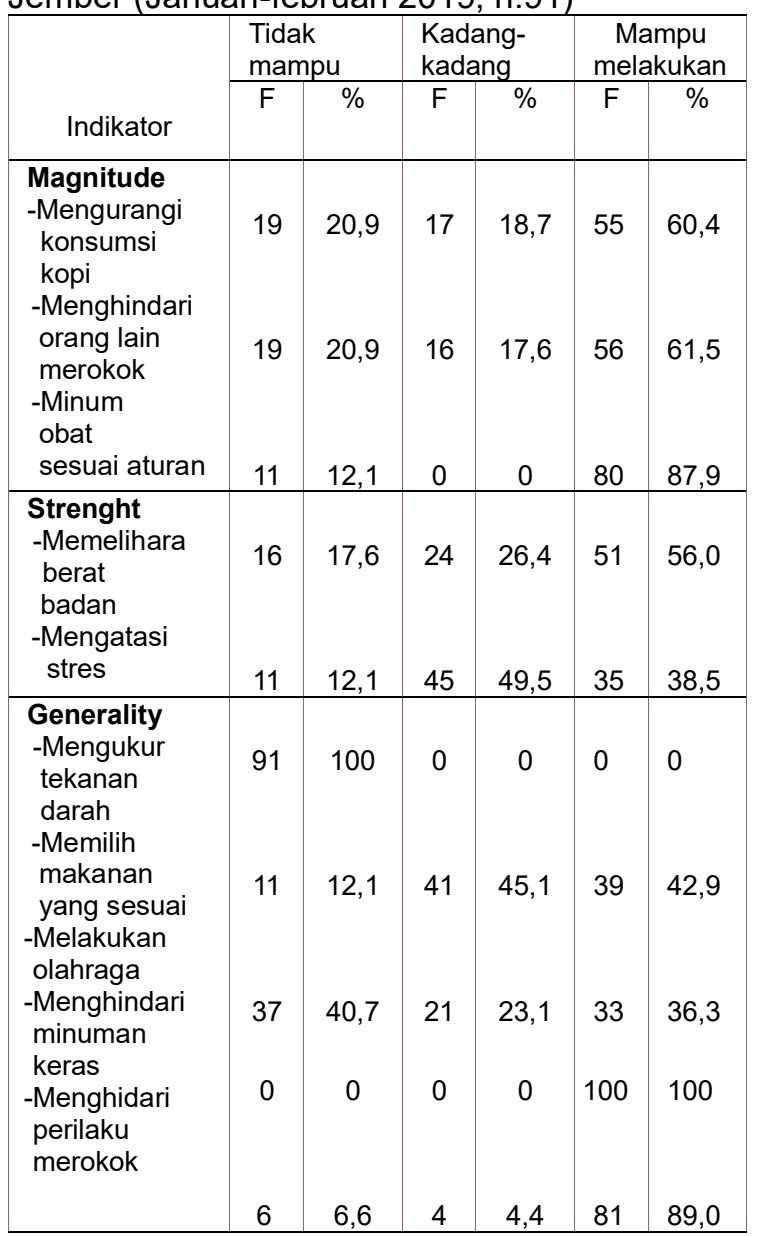

Sumber: Data Primer Penelitian, JanuariFebruari 2019

Tabel 5 didapatkan hasil bahwa pada Indikator tingkat kesulitan (magnitude) dengan jawaban tidak mampu, terbanyak pada pernyataan terkait kemampuan responden dalam mengurangii konsumsi kopi dan menghindari orang lain yang sedang merokok yaitu 20,9 \%. Indikator kekuatan (strength) dengan jawaban tidak mampu, terbanyak pada pernyataan terkait kemampuan responden dalam memelihara berat badan dan indikator cakupan tingkah laku (generality) dengan jawaban tidak mampu, terbanyak pada pernyataan terkait kemampuan responden dalam mengukur tekanan darah menggunakan tensimeter digital.

Kualitas Hidup

Tabel 6. Distribusi Kualitas Hidup Pasien Hipertensi di Wilayah Kerja Puskesmas Silo Jember (Januari-februari 2019; n:91)

\begin{tabular}{|c|c|c|}
\hline Variabel & $\begin{array}{c}\text { Jumlah } \\
\text { (Orang) }\end{array}$ & Presentase (\%) \\
\hline $\begin{array}{c}\text { Kualitas Hidup } \\
\text { a. Sangat Buruk }\end{array}$ & 0 & 0 \\
\hline
\end{tabular}




\begin{tabular}{|c|c|c|}
\hline b. Buruk & 0 & 0 \\
\hline c. Sedang & 64 & 70,3 \\
\hline d. Baik & 27 & 29,7 \\
\hline e. Sangat Baik & 0 & 0 \\
\hline
\end{tabular}

Sumber: Data Primer Penelitian, JanuariFebruari 2019

Tabel 6 Distribusi Kualitas hidup pasien hipertensi di Wilayah Kerja Puskesmas Silo Jember terbanyak pada kategori sedang yaitu 64 pasien dengan presentase $70,3 \%$.

\section{Pembahasan \\ Efikasi Diri}

Berdasarkan hasil penelitian yang dilakukan pada 91 pasien hipertensi di wilayah kerja Puskesmas Silo Jember, menunjukkan hasil bahwa efikasi diri pada kategori baik yaitu 70 pasien dengan presentase sebesar $76,9 \%$. Sedangkan efikasi diri buruk sebanyak 21 pasien dengan presentase $23,1 \%$. Penelitian ini sejalan dengan penelitian yang dilakukan pada seluruh pasien hipertensi di Mutiara Homecare Kota Medan dari 130 responden menunjukkan bahwa mayoritas responden memiliki efikasi diri baik sebanyak 126 orang dengan presentase $96,1 \%$ [13].

Efikasi diri yang baik akan meningkatkan cara penyelesaian masalah, menurunkan rasa takut akan kegagalan, dan memiliki semangat tinggi dalam menjalankan sesuatu [14]. Efikasi diri yang dimiliki seseorang dapat dilihat dari beberapa sumber yaitu dari pengalaman sendiri, pengalaman orang lain, Persuasi verbal dan Kondisi fisiologis [15]. Hasil penelitian menunjukkan efikasi diri pada kategori baik. Efikasi diri baik tersebut salah satunya dapat bersumber dari persuasi verbal atau nasehat. Puskesmas Silo Jember memiliki kegiatan rutin berupa program pengelolaan penyakit kronis dan posyandu lansia. Dari 91 responden 77 orang mengikuti kegiatan. Adanya program tersebut dapat memberikan semangat atau nasihan untuk meyakinkan responden agar mampu melakukan aktivitas atau perilaku yang berkaitan dengan penyakit hipertensi.

Hasil penelitian menunjukkan bahwa 21 responden dalam kategori efikasi diri buruk. Dari 91 responden, 14 responden tidak mengikuti serangkaian kegiatan yang diadakan puskesmas. Peneliti berasumsi bahwa salah satu faktor yang menyebabkan efikasi diri buruk salah satunya adalah sumber efikasi. Dapat disebabkan karena pengalaman yang buruk, pengalaman orang lain maupun kondisi fisiologisnya. Berdasarkan teori, harapan yang lemah bisa disebabkan oleh pengalaman yang buruk [14].

Efikasi diri buruk juga dapat dinilai dari beberapa indikator efikasi diri, Indikator tingkat kesulitan dengan jawaban tidak mampu, terbanyak pada pernyataan terkait kemampuan mengurangi konsumsi kopi dan menghindari orang lain yang merokok yaitu $20,9 \%$. Kopii berbahaya bagi penderita hipertensi karena senyawa kafein bisa menyebabkan tekanan darah meningkat [16]. Individu dengan kebiasan merokok memiliki kecenderungan menderita hipertensi [17]. Indikator kekuatan dengan jawaban tidak mampu, terbanyak pada pernyataan kemampuan dalam memelihara berat badan dan indikator cakupan tingkah laku dengan jawaban tidak mampu, terbanyak pada pernyataan terkait kemampuan dalam mengukur tekanan darah menggunakan tensimeter digital.

Peneliti menyimpulkan bahwa pada penelitian ini efikasi diri pasien hipertensi di Wilayah Kerja Puskesmas Silo Jember pada kategori baik. Peneliti berasumsi bahwa individu dengan efikasi diri yang baik akan memiliki koping yang positif dan mampu mencapai tujuan yang diinginkan.

\section{Kualitas Hidup}

Hasil penelitian ini menunjukkan bahwa kualitas hidup pasien hipertensi di wilayah kerja Puskesmas Silo Jember pada kategori sedang yaitu $70,3 \%$. Penelitian terkait kualitas hidup pasien hipertensi di wilayah kerja puskesmas sidomulyo kecamatan tampan pekanbaru menunjukkan bahwa dari 33 responden memiliki kualitas hidup baik yaitu $54,1 \%$ [18].

Hasil yang menyatakan kualitas hidup penderita hipertensi di wilayah kerja Puskesmas Silo Jember pada kategori sedang, dapat dinilai dari keempat domain kualitas hidup yaitu domain fisik, psikologis, hubungan sosial dan lingkungan. Kualitas hidup kesehatan fisik yang baik dapat tercapai dan terpelihara jika pasien dapat mengontrol penyakitnya secara teratur [19]. Psikologis individu dengan hipertensi yang memiliki optimisme dapat mengurangi pandangan negatif terhadap masalah sehingga menimbulkan perasaan mampu menghadapi masalah kesehatan untuk mencapai kualitas hidup yang lebih baik [20]. Dukungan sosial yang diberikan oleh teman sebaya akan memotivasi untuk lebih baik dalam melakukan aktivitas sehari-hari maupun masalah yang dihadapinya. Menurut internasional classification of functioning, disability and health (ICF), rumah dengan lingkungan yang tidak bermasalah memiliki kualitas hidup baik [18].

Adapun beberapa faktor yang dapat mempengaruhi kualitas hidup pasien hipertensi yaitu usia, tingkat pendidikan, jenis kelamin, status perkawinan, lama menderita, dan efikasi 
diri. Peneliti berasumsi bahwa keyakinan diri dapat berperan penting pada kualitas hidup, dimana keyakinan diri pasien hipertensi di wilayah kerja Puskesmas Silo Jember salah satunya bersumber dari kegiatan yang diadakan puskesmas.

\section{Hubungan antara Efikasi Diri dengan Kualitas Hidup Pasien Hipertensi \\ Berdasarkan penelitian di dapatkan hasil} $p$-value sebesar 0,001 yang artinya terdapat hubungan antara efikasi diri dengan kualitas hidup pasien hipertensi di wilayah kerja Puskesmas Silo Jember. Hasil penelitian serupa terkait hubungan antara efikasi diri dengan manajemen perawatan diri pada penderita hipertensi dewasa di kabupaten jepara, dalam penelitiannya dijelaskan bahwa efikasi diri secara bermakna berhubungan dengan manajemen perawatan diri hipertensi. Para responden yang memiliki percaya diri yang tinggi dilaporkan dapat melakukan manajemen perawatan diri hipertensi yang lebih baik [21].

Berdasarkan hasil penelitian didapatkan hasil bahwa efikasi diri pasien hipertensi di wilayah kerja Puskesmas Silo Jember sebagian besar memiliki efikasi diri baik sebesar 76,9\%. Hasil penelitian menunjukkan bahwa kualitas hidup pasien hipertensi di wilayah kerja Puskesmas Silo Jember mayoritas pada kategori sedang yaitu $70,3 \%$. Penelitian ini di dukung dari penelitian terkait efektivitas efikasi diri terhadap peningkatan kualitas hidup klien dengan penyakit kronik, bahwa efikasi diri merupakan manajemen diri dari klien yang jika dapat dioptimalkan secara baik dapat mempengaruhi kualitas hidup pada proses pengobatan klien yang lama [4]. Efikasi diri dapat dikatakan sebagai keyakinan dalam meningkatkan kualitas hidup pasien hipertensi dalam menghadapi penyakit yang sedang dialaminya [22].

Semakin tinggi efikasi diri maka semakin tinggi koping pada pendertita hipertensi. Efikasi diri yang dimiliki oleh penderita hipertensi memungkinkan dirinya memiliki motivasi untuk bertindak dan berusaha untuk sembuh [5]. Sesuai dengan penelitian yang yang menyatakan bahwa efikasi diri adalah sebuah faktor penentu dalam sebuah managemen diri dari individu pengidap penyaki kronik. Individu yang memiliki efikasi diri yang tinggi akan membantu meningkatkan kualitas hidupnya, sehingga individu tersebut dapat menjalankan kehidupannya dengan baik meskipun menderita penyakit hipertensi. Pada penderita hipertensi dengan efikasi diri yang tinggi dalam menghadapi penyakitnya maka akan mudah dalam menjalani kehidupan sehari-harinya [24].
Peneliti berasumsi bahwa Semakin tinggi efikasi diri yang dimiliki maka semakin tinggi tujuan yang ingin dicapai. Semakin tinggi efikasi diri akan membuat individu semakin percaya bahwa penyakit yang sedang diderita, setelah melakukan serangkaian proses pengobatan akan membuat individu tersebut lebih terkontrol dan sembuh. Efikasi diri yang baik mampu meningkatkan kemampuan melakukan aktivitas sehari-hari, meningkatkan kesehatan, kesejahteraan, dan kepercayaan diri.

\section{Simpulan dan Saran}

Terdapat hubungan antara efikasi diri dengan kualitas hidup pasien hipertensi di wilayah kerja Puskesmas Silo Jember.

Peneliti selanjutnya diharapkan menggunakan jumlah sampel yang lebih banyak. Selain itu mampu meneliti faktor lain yang dapat berhubungan dengan kualitas hidup pasien hipertensi seperti lama menderita hipertensi dan komplikasi pasien hipertensi. Hasil penelitian ini dapat di jadikan tambahan referensi. Pelayanan kesehatan diharapkan mampu melakukan berbagai edukasi terkait hipertensi dan faktor yang dapat mempengaruhi kualitas hidup pasien hipertensi. Diharapkan masyarakat mampu memanfaatkan dengan baik beberapa rangkaian kegiatan yang diadakan oleh puskesmas seperti posyandu lansia maupun program pengelolaaan penyakit kronis (Prolanis), kegiatan tersebut dapat bermanfaat dalam mengontrol penyakit yang sedang dialami.

\section{Daftar Pustaka}

[1] Aspiani RY. Buku Ajar Asuhan Keperawatan Klien Gangguan Kardiovaskular Aplikasi NIC \& NOC. Jakarta: ECG; 2014.

[2] Poluan Marco AD, Kalesaran Angela FC, \& Ratag BT. Hubungan antara hipertensi dengan kualitas hidup pada penduduk di kelurahan kinilow kecamatan tomohon utara kota tomohon. Jurnal media kesehatan [Internet]. 2017 [cited 15 September 2018]; 9 (3): [pp. 18].

[3] Adedapo AD, Akunne OO, \& Adedokun BO. Comparative assessment of determinants of health-related quality of life in hypertensive patients and normal population in south-west nigeria. Int. Journal of Clinical Pharmacology and Therapeutics [Internet]. 2015 [cited 20 September 2018]; 53(03): [pp. 265-271].

[4] Afandi AT, \& Kurniyawan EH. Efektivitas 
self efficacy terhadap kualitas hidup klien dengan diagnosa penyakit kronik. Jurnal akademisi Program Studi IImu Keperawatan Universitas Jember [internet]. 2017 [cited 15 September 2018]; [pp. 23-30].

[5] Sutarinik S, Pitayanti A, \& Maunaturrohmah A. Hubungan efikasi diri (self efficacy) dengan problem focussed coping pasien hipertensi. Nursing Journal of STIKES Insan Cendekia Medika Jombang [Internet] 2017. [cited 20 September 2018]; 13 (1): [pp. 15-23].

[6] Mersal FA, \& Mersal NA. Effect of Evidence Based Lifestyle Guidelines on Self Efficacy of Patients with Hypertension. Internasional journal of current microbiology and applied sciences [Internet] 2015. [cited 23 September 2018]; 4 (3): [pp. 244-263].

[7] Kementrian kesehatan Republik Indonesia [Internet]. Jakarta: Buletin Jendela Data \& Informasi Kesehatan; 2012 [cited 20 September 2018].

[8] Kementrian kesehatan Republik Indonesia [Internet]. Jakarta: Sebagian besar penderita hipertensi tidak menyadarinya; 2017 [cited 20 September 2018] Available from: Jakarta:

http://www.depkes.go.id/article/view/170 51800002/sebagian-besar-penderitahipertensi-tidak-menyadarinya.html

[9] Daniali SS, Darani FM, Eslami AA, \& Mazaheri M. Relationship between selfefficacy and physical activity, medication adherence in chronic disease patients. Advanced Biomedical Research [Internet]. 2017 [cited 20 Oktober 2018]; 6(1): [pp. 63].

[10] Okatiranti O, Irawan E, \& F Amelia. Hubungan self efficacy dengan perawatan diri lansia hipertensi. Jurnal Keperawatan BSI [Internet]. 2017 [cited 10 Maret 2019]; 5(2): [pp. 130-139].

[11] Sulistyarini I. Terapi relaksasi untuk menurunkan tekanan darah dan meningkatkan kualitas hidup penderita hipertensi. Jurnal Psikologi [Internet]; 2013 [cited 10 Oktober 2018]; 40(1): [pp. 28-38].

[12] Zhang Y, Zhongliang Z, Gao J, Wang D, Zhang Q, Zhiying Z, Su M, \& Li D. Health-related quality of life and its influencing factors for patients with hypertension: evidence from the urban and rural areas of shaanxi province, china. BMC Health Services Research [Internet]. 2016 [cited 20 November
2018]; 16(1): [pp. 1-9].

[13] Amila A, Sinaga J, \& Sebiring E. Self Efficacy dan Gaya Hidup Pasien Hipertensi. Jurnal Kesehatan [Internet]. 2018 [cited 10 Maret 2019]; 9(3): [pp. 360-365].

[14] Putra Putu SP, \& Susilawati LKPA. Hubungan antara dukungan sosial dan self efficacy dengan tingkat stres pada perawat di rumah sakit umum pusat sanglah. Jurnal Psikologi Udayana [Internet]. 2018 [cited 20 Oktober 2019]; 5(1): [pp. 145-157].

[15] Lenz EK \& Bagget Lillie MS. Self-efficacy in nursing: research and measurement perspectives. New york: Springer publishing company; 2002.

[16] Insan Andi NM \& Kurniawaty E. Pengaruh kopi terhadap hipertensi. Jurnal kedokteran universitas lampung [Internet]. 2016 [cited 11 April 2019]; 2(2): [pp. 6-10].

[17] Sudhana IW, dan Narayana IPA. Gambaran kebiasaan merokok dan kejadian hipertensi pada masyarakat dewasa di wilayah kerja puskesmas pekutatan 1 tahun 2013. Jurnal universitas udayana [Internet]. 2013 [cited 20 November 2018]; 4(2): [pp. 111].

[18] Azmi N, Karim D, \& Nauli FA. Gambaran kualitas hidup lansia dengan hipertensi di wilayah kerja puskesmas sidomulyo kecamatan tampan pekanbaru. Jurnal fakultas keperawatan universitas riau [Internet]. 2018 [cited 15 Maret 2019]; 5(2): [pp. 439-448].

[19] Dewi PR, \& Sudhana IW. Gambaran kualitas hidup pada lansia dengan normotensi dan hipertensi di wilayah kerja puskesmas gianyar i periode bulan november tahun 2013. E-jurnal medika udayana [Internet]. 2013 [cited 10 Maret 2019]; 3(9): [pp. 1-13].

[20] Anbarasan SS. Gambaran kualitas hidup lansia dengan hipertensi di wilayah kerja puskesmas rendang pada periode 27 februari sampai 14 maret 2015. Journal of Science and Medical Research [Internet]. 2015 [cited 20 November 2018]; 4(1); [pp. 113-124].

[21] Huda S. Hubungan antara efikasi diri dengan manajemen perawatan diri pada penderita hipertensi dewasa di kabupaten jepara. Jurnal keperawatan dan kesehatan masyarakat stikes cendekia utama kudus [Internet]. 2017 [cited 26 Februari 2019]; 2(5): [pp. 1-10].

[22] Huang L, Li L, Zhang Y, Li H, Li X, \& Wang $H$. Self-Efficacy, Medication 
Adherence, and Quality of Life Among People Living With HIV in Hunan Province of China: A Questionnaire
Survey. Journal of the association of nurses in aids care [Internet]. 2013 [cited 25 Februari 2019]; 24(2): [pp. 145-153]. 